\title{
Differential Regulation of Insulin Receptor Substrates-1 and -2 (IRS-1 and IRS-2) and Phosphatidylinositol 3-Kinase Isoforms in Liver and Muscle of the Obese Diabetic (ob/ob) Mouse
}

\author{
Nada J. Kerouz, Dieter Hörsch, Sebastian Pons, and C. Ronald Kahn \\ Research Division, Joslin Diabetes Center, and Department of Medicine, Harvard Medical School, Boston, Massachusetts 02215
}

\begin{abstract}
Intracellular insulin signaling involves a series of alternative and complementary pathways created by the multiple substrates of the insulin receptor (IRS) and the various isoforms of $\mathrm{SH} 2$ domain signaling molecules that can interact with these substrates. In this study, we have evaluated the roles of IRS-1 and IRS-2 in signaling to the phosphatidylinositol (PI) 3-kinase pathway in the ob/ob mouse, a model of the insulin resistance of obesity and non-insulin-dependent diabetes mellitus. We find that the levels of expression of both IRS-1 and IRS- 2 are decreased $\sim 50 \%$ in muscle, whereas in liver the decrease is significantly greater for IRS-2 (72\%) than for IRS-1 (29\%). This results in differential decreases in IRS-1 and IRS-2 phosphorylation, docking of the p85 $\alpha$ regulatory subunit of PI 3-kinase, and activation of this enzyme in these two insulin target tissues. In $o b / o b$ liver there is also a change in expression of the alternatively spliced isoforms of the regulatory subunits for PI 3-kinase that was detected at the protein and mRNA level. This resulted in a $45 \%$ decrease in the p85 $\alpha$ form of PI 3-kinase, a ninefold increase in the AS53/p55 $\alpha$, and a twofold increase in p50 $\alpha$ isoforms. Thus, there are multiple alterations in the early steps of insulin signaling in the $o b / o b$ mouse, with differential regulation of IRS-1 and IRS-2, various PI 3-kinase regulatory isoforms, and a lack of compensation for the decrease in insulin signaling by any of the known alternative pathways at these levels. (J. Clin. Invest. 1997. 100:31643172.) Key words: diabetes • insulin receptor kinase • insulin resistance $\bullet$ phosphatidylinositol 3-kinase • insulin receptor substrate
\end{abstract}

\section{Introduction}

Insulin resistance and obesity are classical features of type II, non-insulin-dependent diabetes mellitus (NIDDM). ${ }^{1}$ These

Address correspondence to C. Ronald Kahn, M.D., Research Director, Joslin Diabetes Center, One Joslin Place, Boston, MA 02215. Phone: 617-732-2635; FAX: 617-732-2593; E-mail: kahnr@joslab. harvard.edu

Received for publication 1 May 1997 and accepted in revised form 8 October 1997.

1. Abbreviations used in this paper: IRS, insulin receptor substrate; NIDDM, non-insulin-dependent diabetes mellitus; PI, phosphatidylinositol; pY, phosphotyrosine.

J. Clin. Invest.

(C) The American Society for Clinical Investigation, Inc. 0021-9738/97/12/3164/09 \$2.00

Volume 100, Number 12, December 1997, 3164-3172

http://www.jci.org characteristics are present in most humans with the disease, as well as in the most commonly used animal models, such as the $o b / o b$ mouse, the $d b / d b$ mouse, and the Zucker fatty rat (1-4). Previous studies examining the early steps in the insulin action cascade have shown that insulin binding is decreased in both the liver and muscle of $o b / o b$ mice due to a decrease in the insulin receptor number $(1,5)$. This results in a decrease in autophosphorylation of the receptor $\beta$ subunit, as well as a decrease in insulin receptor substrate-1 (IRS-1) phosphorylation and IRS-1-associated phosphatidylinositol (PI) 3-kinase activity $(5,6)$.

Over the past few years, there has been an increase in our understanding of the molecular mechanisms of insulin action with increasing evidence of a complex signaling network using alternative or complementary pathways and multiple molecular isoforms of key signaling molecules (7-9). For example, the recent cloning of IRS-2 (4PS) has demonstrated a second substrate of the receptor that shares many features present in IRS-1 (10). In mice made IRS-1-deficient by homologous recombinant gene targeting, IRS-2 serves as an alternate substrate and allows for significant residual insulin and IGF-1 signaling (11-13).

IRS-1 and IRS-2 link the insulin receptor to its final biological actions via a series of intermediate effectors which bind to the tyrosine-phosphorylated motifs in IRS proteins via $\mathrm{SH} 2$ domains. One of the best studied $\mathrm{SH} 2$ domain proteins is the enzyme PI 3-kinase. This enzyme is stimulated by a number of growth factors, and, in the case of insulin, has been shown to play a critical role in many of the metabolic effects of the hormone, including stimulation of glucose transport, activation of glycogen synthase, and inhibition of the key enzyme of gluconeogenesis, phosphoenol pyruvate carboxykinase (PEPCK) $(7,14)$. PI 3-kinase is composed of a regulatory subunit that binds to IRS-1/IRS-2 via SH2 domains and a $110-\mathrm{kD}$ catalytic subunit that phosphorylates PI and its $4^{\prime}$ and $4^{\prime}, 5^{\prime}$ phosphorylated derivatives in the D-3 position of the inositol ring (1523). Initially, only two subunits of $85 \mathrm{kD}$ were characterized as regulatory subunits of PI 3-kinase. These were referred to as $\mathrm{p} 85 \alpha$ and $\mathrm{p} 85 \beta$ and are the products of different genes (20-22). However, recent studies from our laboratory (24) and others (25-27) have revealed several additional isoforms of $\mathrm{p} 85 \alpha$. These include 53- and 50-kD isoforms termed AS53 (also termed $\mathrm{p} 55 \alpha$ ) and $\mathrm{p} 50 \alpha$, respectively, which are the result of alternative splicing of the p85 $\alpha$ gene. Furthermore, a novel 55$\mathrm{kD}$ protein ( $\left.\mathrm{p} 55^{\mathrm{PIK}}\right)$, the product of a different gene, has been characterized as a regulatory subunit of PI 3-kinase (28). These isoforms have a distinct tissue expression and alterations in their primary sequence that have been suggested to play a role in specificity of signaling or, in some cases, differential localization within the cell (24-28).

In this study, we have characterized the role of these alternative signaling pathways in the insulin resistance of the obese hyperglycemic $(o b / o b)$ mouse. We find that not only are there quantitative differences in the regulation of the IRS proteins, 
but also dramatic changes in the isoforms of PI 3-kinase expressed in the liver of the $o b / o b$ mouse, which contribute to multiple levels of alteration in insulin signaling in this insulinresistant state.

\section{Methods}

Materials. Reagents for SDS-PAGE and immunoblotting were from Bio-Rad (Richmond, CA). Hepes, PMSF, aprotinin, leupeptin, benzamidine hydrochloride, DTT, ATP, Triton X-100, Tween 20, glycerol, and BSA (fraction V) were from Sigma Chemical Co. (St. Louis, MO). NP-40 was from Calbiochem (La Jolla, CA), PI from Avanti Polar Lipids (Alabaster, AL), silica gel thin-layer chromatography plates from Merck (Gibbstown, NJ), protein A-Sepharose 6MB from Pharmacia (Uppsala, Sweden), ${ }^{125}$ I-protein A from ICN Biomedicals (Costa Mesa, CA), and $\left[\gamma^{-32} \mathrm{P}\right]$ ATP and $\left[\alpha-{ }^{32} \mathrm{P}\right] \mathrm{dCTP}$ from NEN-DuPont (Wilmington, DE). Nitrocellulose paper (BA 85, $0.2 \mu \mathrm{m}$ ) and NYTRAN nylon membrane were from Schleicher \& Schuell (Keene, NH). Sodium pentobarbital was from Abbott Laboratories (South Pasadena, CA) and human recombinant insulin (Humulin R) was from Eli Lilly \& Co. (Indianapolis, IN). Monoclonal antiphosphotyrosine (pY) antibody (4G10), anti-PI 3-kinase (anti-p85), and antibodies to the $\mathrm{COOH}$-terminal sequence (TYASINFQKQPEDRQ) corresponding to residues $1221-1235$ of the rat liver IRS-1 protein were obtained as previously described (29). Antibodies to recombinant IRS-2 and murine p85 cDNA were a generous gift of Morris White (Joslin Diabetes Center, Boston, MA). Ultraspec RNA isolation system was purchased from Biotecx (Houston, TX). Poly $(\mathrm{A})^{+}$mRNA isolation kit was from Ambion (Austin, TX). An unidirectional mouse brain dTprimed cDNA library in the Uni-ZAP XR vector, Pfu-polymerase, and the PCR-script cloning vector were from Stratagene (La Jolla, CA). dNTPs were from Pharmacia. The PCR II cloning system was from Invitrogen (Carlsbad, CA). A random labeling kit was from Amersham (Arlington Heights, IL).

Animals. Male obese hyperglycemic mice (C57B1/6J ob/ob) and their lean matched controls $(o b /+)$ were purchased from The Jackson Laboratory (Bar Harbor, ME). The mice (8-10-wk old) were fed standard rodent chow and water ad libitum. Food was withdrawn 10$12 \mathrm{~h}$ before experiments. Mice were anesthetized with $100 \mathrm{mg} / \mathrm{kg}$ of sodium pentobarbital injected intraperitoneally. Following loss of pedal and corneal reflexes, $5 \mathrm{U}(0.2 \mathrm{mg})$ of regular human insulin or its diluent was injected into the portal vein. The liver, gastrocnemius, and quadriceps muscles were excised 1 and 3 min after insulin (or its diluent) injection, respectively, and frozen in liquid nitrogen.

Immunoprecipitation and Western blotting. The frozen tissue was homogenized in ice-cold lysis buffer ([1\% Triton X-100, $10 \%$ glycerol, 1\% NP-40, $50 \mathrm{mM}$ Hepes, $\mathrm{pH} 7.4,100 \mathrm{mM}$ sodium pyrophosphate, $100 \mathrm{mM}$ sodium fluoride, $10 \mathrm{mM}$ EDTA, $5 \mathrm{mM}$ sodium vanadate, aprotinin $(10 \mu \mathrm{g} / \mathrm{ml})$ leupeptin $(5 \mu \mathrm{g} / \mathrm{ml})$, benzamidine $(1.5 \mathrm{mg} /$ $\mathrm{ml})$ and PMSF $(34 \mu \mathrm{g} / \mathrm{ml})]$ using a Polytron PTA 20 S generator operated at maximum speed for $30 \mathrm{~s}$. The insoluble material was removed by centrifugation at $55,000 \mathrm{rpm}$ in a $70 \mathrm{Ti}$ rotor (Beckman Instruments, Inc., Fullerton, CA) for $60 \mathrm{~min}$, and equal protein amounts of the supernatant were subjected to immunoprecipitation for $2 \mathrm{~h}$ using the indicated antibodies. Subsequently, protein A-Sepharose was added for another hour. The samples were processed for SDS-PAGE electrophoresis and Western blotting as previously described (6). Under the conditions used, the $\alpha$-IRS- 1 antibody precipitated $65 \%$ of the IRS- 1 in muscle and $59 \%$ of the IRS-1 in liver. Based on other studies, this is associated with no detectable IRS-2. The $\alpha$-IRS- 2 is less effective in precipitation (30-37\%) depending on cell type, and does coprecipitate a small amount $(<7 \%)$ of IRS-1.

PI 3-kinase activity. Immune-complexed PI 3-kinase activity was measured by in vitro phosphorylation of PI as previously described (6). Immune complexes were incubated in a $65-\mu 1$ reaction containing $440 \mu \mathrm{M}$ ATP $\left(30 \mu \mathrm{Ci}\left[{ }^{32} \mathrm{P}\right] \mathrm{ATP}\right.$ and $5 \mu \mathrm{g}$ of PI). After $10 \mathrm{~min}$ at room temperature with constant shaking, the reaction was stopped by the addition of $20 \mu l 8 \mathrm{~N} \mathrm{HCl}$ and $160 \mu \mathrm{CHCl}_{3} /$ methanol (1:1). The samples were centrifuged, and the lower organic phase was removed and applied to a silica gel TLC plate (Merck, St. Louis, MO) coated with $1 \%$ potassium oxalate. TLC plates were developed in $\mathrm{CHCl}_{3} /$ $\mathrm{CH}_{3} \mathrm{OH} / \mathrm{H}_{2} \mathrm{O} / \mathrm{NH}_{4} \mathrm{OH}$ (60:47:11.3:2), dried, and visualized by autoradiography. The ${ }^{32} \mathrm{P}$-labeled 3-phosphatidylinositides were quantitated using a PhosphorImager (Molecular Dynamics, Inc., Sunnyvale, CA).

Cloning of cDNA probes. A murine $\mathrm{p} 85 \alpha$-specific subclone spanning 423 nucleotides (nt) downstream of the start codon was generated by PCR using $100 \mathrm{ng}$ of mouse p $85 \alpha \mathrm{cDNA}$ as a template, a $5^{\prime}$ primer corresponding to nt 556-577 (5'-atg agt gca gag ggc tac cag- $3^{\prime}$ ) and a $3^{\prime}$-primer corresponding to nt $958-979\left(5^{\prime}\right.$-ctt ctc aat ggc ttc cag gag-3) of the p $85 \alpha$ cDNA sequence (20). In addition, a 572-nt subclone corresponding to the $\mathrm{COOH}$-terminal SH2 domain of $\mathrm{p} 85 \alpha$ was produced by PCR. The $5^{\prime}$-primer $\left(5^{\prime}\right.$-aga acg gct atc gaa gca- $\left.3^{\prime}\right)$ was identical to nt 1997-2015 and the $3^{\prime}$-primer (5'-gac gca atg ctt gac ttc$\left.3^{\prime}\right)$ corresponded to nt $2552-2569$ of p $85 \alpha$ (20). Both PCR products were cloned into the PCR II vector. The complete coding sequence of murine AS53 was cloned by PCR using $1 \mu \mathrm{g}$ of DNA from a $\lambda$ mouse brain cDNA library as a template with $5^{\prime}$-primer identical to nt $1-20$ of the rat AS35/p55 $\alpha$ sequence (5'-atg tac acc acg gtt tgg ac-3) and a 3 '-primer (5-tca tcg cct ctg ttg tgc at-3) corresponding to nt 1348-1365 of the rat AS53/p55 $\alpha$ (25). The resulting 1365-nt PCR product was cloned in PCR II. Sequencing of the mouse AS53-cDNA revealed $>91 \%$ identity to the nucleotide sequence of rat AS53/p55 $\alpha$ (25). An AS53-specific subclone was generated by PCR using the same template and $5^{\prime}$-primer, and $3^{\prime}$-primer corresponding to nt 89-106 to rat AS53/p55 $\alpha$ (5'-ctg gtg gat cca ttt cta-3'). The 106-nt PCR product was cloned blunt-ended into PCR-script. A subclone specific for mouse p50 $\alpha$ was produced by PCR using $1 \mu \mathrm{g}$ of murine genomic DNA as a template and $5^{\prime}$-primer identical to nt -182 to -164 of the untranslated murine p50 $\alpha$ sequence (5'-cgg gct gag agt cgc gcg-3) and a $3^{\prime}-$ primer corresponding to nt $1-22$ of the p $50 \alpha$-coding sequence $\left(5^{\prime}\right.$-cag tat ttg cag gtt atg t-3) (27). The resulting 204-nt PCR product was cloned into PCR-script. A p55 ${ }^{\mathrm{PIK}}$-specific subclone (28) was generated from the $\lambda$ mouse brain cDNA library by PCR using $5^{\prime}$-gac agc gcg atg tac aat- $3^{\prime}$ (nt 1361-1383) and $5^{\prime}$-cca tcc cga tga tag gat ctt- $3^{\prime}$ (nt 1710-1730) as $5^{\prime}$ - and $3^{\prime}$-primers, respectively. The 396-nt PCR product was cloned into PCR II. Likewise, part of murine p85 $\beta$ (28) was cloned by PCR using primers $5^{\prime}$-gct gtg gtg acc cet gaa gct-3' and $5^{\prime}$-ctg gta ctg ctg gtg gta gac-3' (corresponding to nt $866-887$ and 1640-1661, respectively). The 795-nt fragment was cloned into PCRscript. A subclone for murine p $110 \alpha$ was generated by PCR using the same template and primers $5^{\prime}$-tgc gct ggg tac tgc gtg gc-3' (corresponding to nt 2701-2720) and 5'-tac gtt caa agc atg ct-3' (nt 31913207) (30). The 506-nt PCR product was cloned into PCR-script. The identity of PCR products was confirmed by sequencing.

RNA extraction and Northern blotting. The Ultraspec RNA isolation system was used to extract total RNA from frozen tissue samples and mRNA was purified using the poly $(\mathrm{A})^{+}$mRNA isolation kit. $40 \mu \mathrm{g}$ of total RNA or $2 \mu \mathrm{g}$ of poly(A) ${ }^{+}$RNA was separated in a denaturing $1 \%$ agarose gel and subjected to Northern blotting using ${ }^{32} \mathrm{P}$ labeled cDNA probes generated by random priming as previously described (29). Blots were exposed overnight with intensifier screens to Kodak XAR film.

\section{Results}

Protein expression and phosphorylation of IRS-1 and IRS-2. IRS-1 and IRS-2 are the major substrates of the insulin receptor kinase in muscle and liver and serve as the primary docking proteins for PI 3-kinase in the insulin signaling network. To determine the level of these relatively nonabundant proteins, homogenates of liver and muscle of the $o b / o b$ mice and their lean littermates were subjected to immunoprecipitation using anti-IRS-1 and anti-IRS-2 antibodies followed by Western immunoblotting with the same antibodies. In both tissues the 

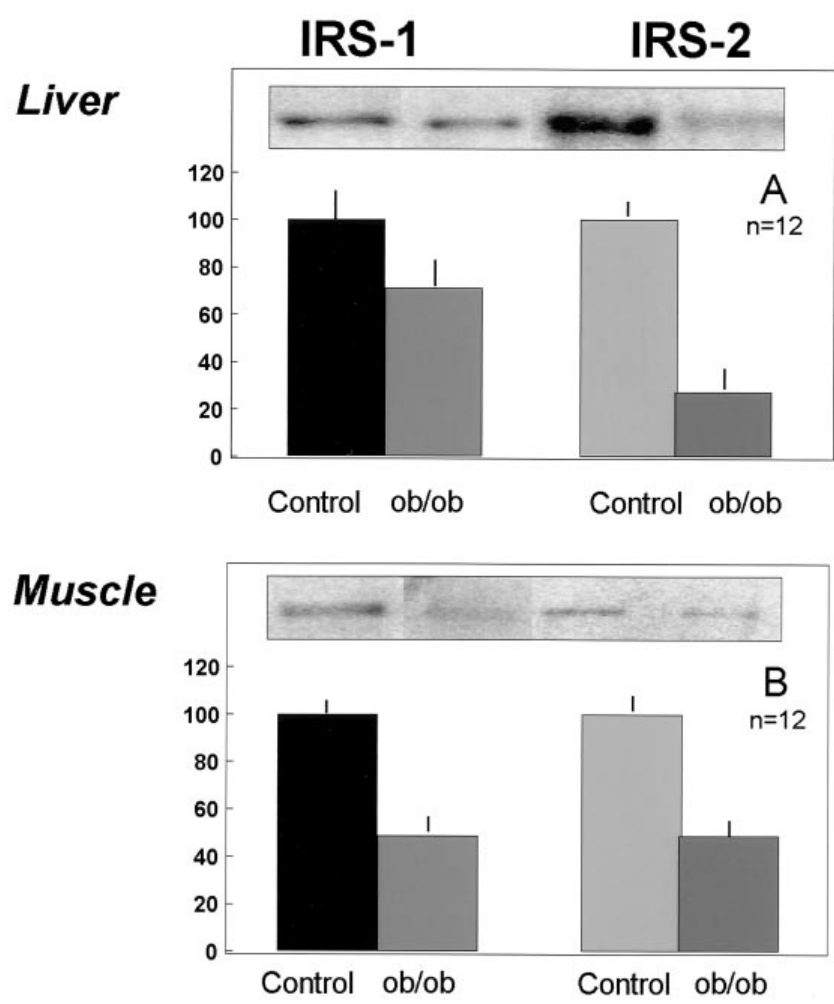

Figure 1. IRS-1 and IRS-2 protein expression in liver and muscle of $o b / o b$ and $o b /+$ control mice. Tissue extraction was performed as described in Methods. Equal amounts of protein were subjected to immunoprecipitation with COOH-terminal IRS- 1 and IRS- 2 antibodies, separated by SDS-PAGE and Western immunoblotted using the same antibodies. The bar graphs show data quantification by ImageQuant (Molecular Dynamics) for results in liver $(A)$ and muscle $(B)$. Data are the mean \pm SEM of 3 independent experiments using 12 animals for each group. They are expressed as relative to control values which were set at $100 \%$.

level of both proteins was decreased in $o b / o b$ mice. In the liver of $o b / o b$ mice, IRS-1 protein expression was decreased by only $29 \%$, whereas IRS-2 was decreased by $72 \%(P<0.0001)$ (Fig. $1 A)$. In $o b / o b$ muscle, expression of IRS-1 and IRS-2 was decreased almost identically by $51 \%(P<0.001$ for both) (Fig. $1 B)$.

To assess tyrosine phosphorylation of these IRSs, liver and muscle homogenates were obtained from control and $o b / o b$ animals before and after insulin stimulation. Lysates were subjected to immunoprecipitation with anti-IRS-1, anti-IRS-2 antibodies, and anti-pY antibodies by Western immunoblotting with anti-pY antibodies. Insulin stimulation resulted in a threefold increase in both IRS-1 and IRS-2 phosphorylation in liver of the control mice (Fig. 2, $A$ and $B$ ). In the liver of $o b / o b$ mice, insulin-stimulated IRS-1 phosphorylation was decreased by $53 \%(P=0.001)$, whereas IRS-2 phosphorylation was decreased by $74 \%(P<0.0001)$ relative to control animals (Fig. $2, A$ and $B$ ). Total IRS phosphorylation pattern as assessed by immunoprecipitation and immunoblotting by anti-pY antibodies and quantification of the bands in the 180-185-kD range showed a threefold increase in phosphorylation upon insulin stimulation in the control group and was decreased by $70 \%$ in livers of the $o b / o b$ animals (Fig. $2 C$ ). In muscle, insulin stimulated phosphorylation of IRS- 1 by sevenfold and IRS- 2 by fourfold in the control lean $(o b /+)$ mice (Fig. 2, $D$ and $E$ ). Insulin-stimulated IRS-1 phosphorylation in muscle was decreased by $68 \%(P=0.001)$ in $o b / o b$ mice as compared with their lean controls (Fig. $2 D$ ), while IRS-2 phosphorylation was decreased by $72 \%$ in muscle of these obese diabetic mice $(P<$ 0.002) (Fig. 2 E). Phosphorylation of all high molecular weight IRSs (pp185) increased 14-fold upon insulin stimulation in $o b /+$ mice. Total substrate phosphorylation pattern upon insulin stimulation was decreased by $72 \%(P<0.0001)$ in muscle of $o b / o b$ animals compared with their lean littermates (Fig. $2 F$ ).

p85 $\alpha$ association and PI 3-kinase activity. To assess p $85 \alpha$ association with IRS-1 and IRS-2, liver and muscle homogenates were subjected to immunoprecipitation with anti-IRS-1, anti-IRS-2, or anti-pY antibodies followed by Western immunoblotting with anti-p85 $\alpha$ antibodies as described in Methods. As previously described $(17,18)$, after tyrosine phosphorylation, there is an increase in p85 $\alpha$ docking that parallels the increase in phosphorylation. In liver of lean $o b /+$ mice, this amounted to a threefold stimulation of association of $\mathrm{p} 85 \alpha$ with IRS-1 and a twofold increase in association for IRS-2 (Fig. 3, $A$ and $B$ ). After insulin stimulation, p85 $\alpha$ association to IRS-1 in liver of $o b / o b$ mice was reduced by $58 \%(P=0.0008)$ compared with control animals (Fig. $3 A$ ). Similarly, association of $\mathrm{p} 85 \alpha$ to IRS-2 was reduced by $64 \%(P<0.0001)$ (Fig. $3 B$ ). Western immunoblotting of anti-pY immunoprecipitates with anti-p85 antibodies revealed a reduction of $47 \%$ $(P<0.03)$ of $\mathrm{p} 85 \alpha$ docking to all pY substrates in liver of $o b /$ $o b$ mice relative to $o b /+$ mice (Fig. $3 C$ ). In the muscle of control mice, insulin stimulation resulted in a 5-fold increase of p $85 \alpha$ association with IRS-1, a 2.5-fold increase in association with IRS-2, and a 15-fold increase in association in total antipY precipitates (Fig. 3, $D-F$ ). In $o b / o b$ mice, a different pattern was observed. Insulin-stimulated association of $\mathrm{p} 85 \alpha$ with IRS-1 was reduced by $53 \%(P<0.0001)$ and association with total pY proteins was decreased by $56.5 \%(P=0.005)$, whereas $\mathrm{p} 85 \alpha$ association with IRS-2 was reduced by only $18.3 \%(P=0.08)$.

PI 3-kinase activity showed changes concordant with p $85 \alpha$ association with IRS- 1 and IRS- 2 in liver and muscle. Thus, in liver of $o b / o b$ mice there was a $61 \%$ reduction in IRS-1-associated PI 3-kinase activity after insulin stimulation as compared with lean control animals $(P<0.002)$ (Fig. $4 A)$ and a $44 \%$ reduction in IRS-2-associated PI 3-kinase activity $(P<0.04)$ (Fig. 4 B). PI 3-kinase activity associated with anti-pY immunoprecipitates in $o b / o b$ mice was also reduced by $\sim 44 \%$ $(P<0.02)$ relative to lean control littermates (Fig. $4 C)$. In skeletal muscle, IRS-1-associated PI 3-kinase activity was markedly reduced by $63 \%(P<0.0001)$ in the obese animals as compared with their control littermates (Fig. $4 D$ ), whereas IRS-2-associated PI 3-kinase activity was decreased only slightly by $35 \%$ (Fig. $4 E$ ), which was similar to the decrease in p $85 \alpha$ docking, but was not statistically significant. However, total PI 3-kinase activity in anti-pY precipitates in muscle was reduced by $64 \%(P<0.002)$, consistent with a greater role for IRS-1 than IRS-2 in PI 3-kinase in muscle (Fig. $4 F$ ).

Expression of $p 85 \alpha$ and $p 85 \alpha$ isoforms. As noted in the Introduction, recent studies have indicated that, in addition to p85 $\alpha$, many tissues express other types of regulatory subunits of PI 3-kinase in the molecular mass range between 50 and $55 \mathrm{kD}$ (24-28). These PI 3-kinase subunits are derived by alternative splicing of the p85 $\alpha$ gene or are the products of separate genes and are expressed in muscle, liver, and other tissues at variable 

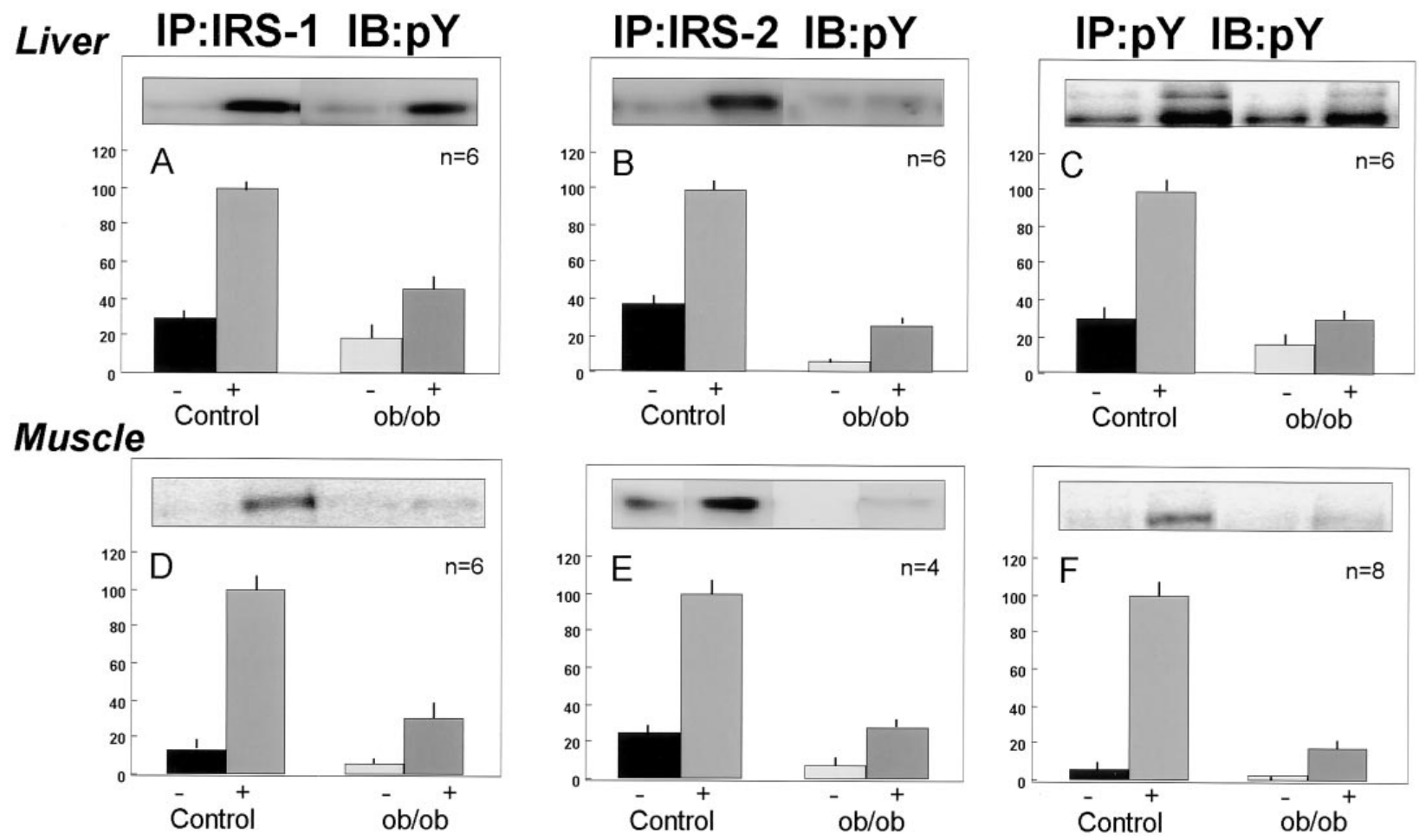

Figure 2. IRS-1, IRS-2, and pY phosphorylation in liver and muscle of $o b / o b$ and $o b /+$ control mice. Animals were injected with $5 \mathrm{U}$ of regular human insulin or its diluent in the portal vein. Liver and muscle tissue were removed 1 and 3 min later, respectively. Equal amounts of protein were subjected to immunoprecipitation with COOH-terminal IRS-1, IRS-2, and pY antibodies, separated by SDS-PAGE and Western immunoblotted with anti-pY antibody. Results for liver are shown in $A-C$. Results in muscle are shown in $D-F$. Tyrosine-phosphorylated bands in $C$ and $F$ correspond to the $185-\mathrm{kD}$ molecular mass range. The bar graphs show data quantification by ImageQuant (Molecular Dynamics). Data are the mean \pm SEM of at least three independent experiments. They are expressed as relative to control, assigning a value of $100 \%$ to the insulin-stimulated control mean.

levels. To determine whether the reduction in PI 3-kinase activity and $\mathrm{p} 85 \alpha$ association with the IRS phosphoproteins in $o b / o b$ mice was associated with a change in $\mathrm{p} 85 \alpha$ or $\mathrm{p} 85 \alpha$ isoform expression, homogenates of liver and muscle were immunoblotted with $\mathrm{p} 85 \alpha$ antibodies either directly or after immunoprecipitation with a polyclonal antibody recognizing the common $\mathrm{SH} 2$ domain region of $\mathrm{p} 85 \alpha$, AS53/p55 $\alpha$, and $\mathrm{p} 50 \alpha$. In muscle homogenates, all three species were detected, with a slight predominance of the lower molecular mass species over $\mathrm{p} 85 \alpha$. However, there was no change in expression of $\mathrm{p} 85 \alpha$ or its isoforms, when $o b / o b$ mice were compared with their lean littermates (data not shown). By contrast, in liver of lean mice, only p $85 \alpha$ and p $50 \alpha$ could be detected, and p $85 \alpha$ was the more prominent of these two by immunoblotting with a common antibody (Fig. 5). In liver of $o b / o b$ mice, this pattern was changed. Thus, $\mathrm{p} 85 \alpha$ expression was reduced by $45 \%$, and there was a twofold increase in the level of $\mathrm{p} 50 \alpha(P<0.0001)$. Even more striking was the appearance of an additional band migrating between 53 and $55 \mathrm{kD}$. This band almost certainly corresponds to AS53 rather than $\mathrm{p} 55^{\mathrm{PIK}}$, since it was strongly positive with an antibody to the common SH2 domains of p85 $\alpha$, AS53, and p50 $\alpha$ (Fig. 5). The level of AS53 in liver of $o b / o b$ mice by immunoblotting was increased ninefold $(P<0.0001)$.

Northern blotting. Since specific antibodies to the alternatively spliced forms of $\mathrm{p} 85 \alpha$ are not yet available, we turned to
Northern blot analysis as a method to confirm which isoforms of PI 3-kinase regulatory subunit were overexpressed and whether the changes in protein expression were secondary to changes at the mRNA level. Using a probe spanning the COOH-terminal SH2-domain that is common to p85 $\alpha$, AS53, and $\mathrm{p} 50 \alpha$, transcripts of $7.4,6.4,4.4,2.8$, and $1.7 \mathrm{~kb}$ were labeled on Northern blots of liver (Fig. $6 A$ ). Using a probe to the specific region of $\mathrm{p} 85 \alpha$ containing the $\mathrm{SH} 3$ domain and bcr-region, the band at $7.4 \mathrm{~kb}$ was clearly labeled (Fig. $6 \mathrm{~B}$ ), while an AS53-specific probe labeled the transcript at $2.8 \mathrm{~kb}$ (Fig. $6 C$ ), and the p50 $\alpha$-specific probe labeled transcripts at 6.4, 2.8 , and $1.7 \mathrm{~kb}$ (Fig. $6 \mathrm{D}$ ). When compared with lean controls, there was a $50 \%$ decrease in the level of the $7.4-\mathrm{kb}$ transcript in liver of $o b / o b$ mice corresponding to the decrease in p85 $\alpha$ protein (Fig. 6, $A$ and $B$ ). In contrast, the transcripts running at 6.4, 2.8, and $1.7 \mathrm{~kb}$, corresponding to AS53 and p50 $\alpha$, were clearly increased in $o b / o b$ liver RNA (Fig. 6, $A, C$, and $D$ ). Using the specific probes, the AS53 signal was upregulated fourfold in liver of $o b / o b$ mice and the p50 $\alpha$ mRNA species increased by threefold (Fig. 6, $C$ and $D$ ). No significant changes were observed in the levels of mRNA for the $\mathrm{p} 85 \beta$ regulatory subunit and the p110 $\alpha$ catalytic subunit (Fig. $6, F$ and $G$ ). The levels of P55 ${ }^{\mathrm{PIK}}$ were very low in liver RNA and also did not change significantly (Fig. $6 \mathrm{E}$ ), but were clearly detectable in brain RNA at $5.8 \mathrm{~kb}$ (not shown). 

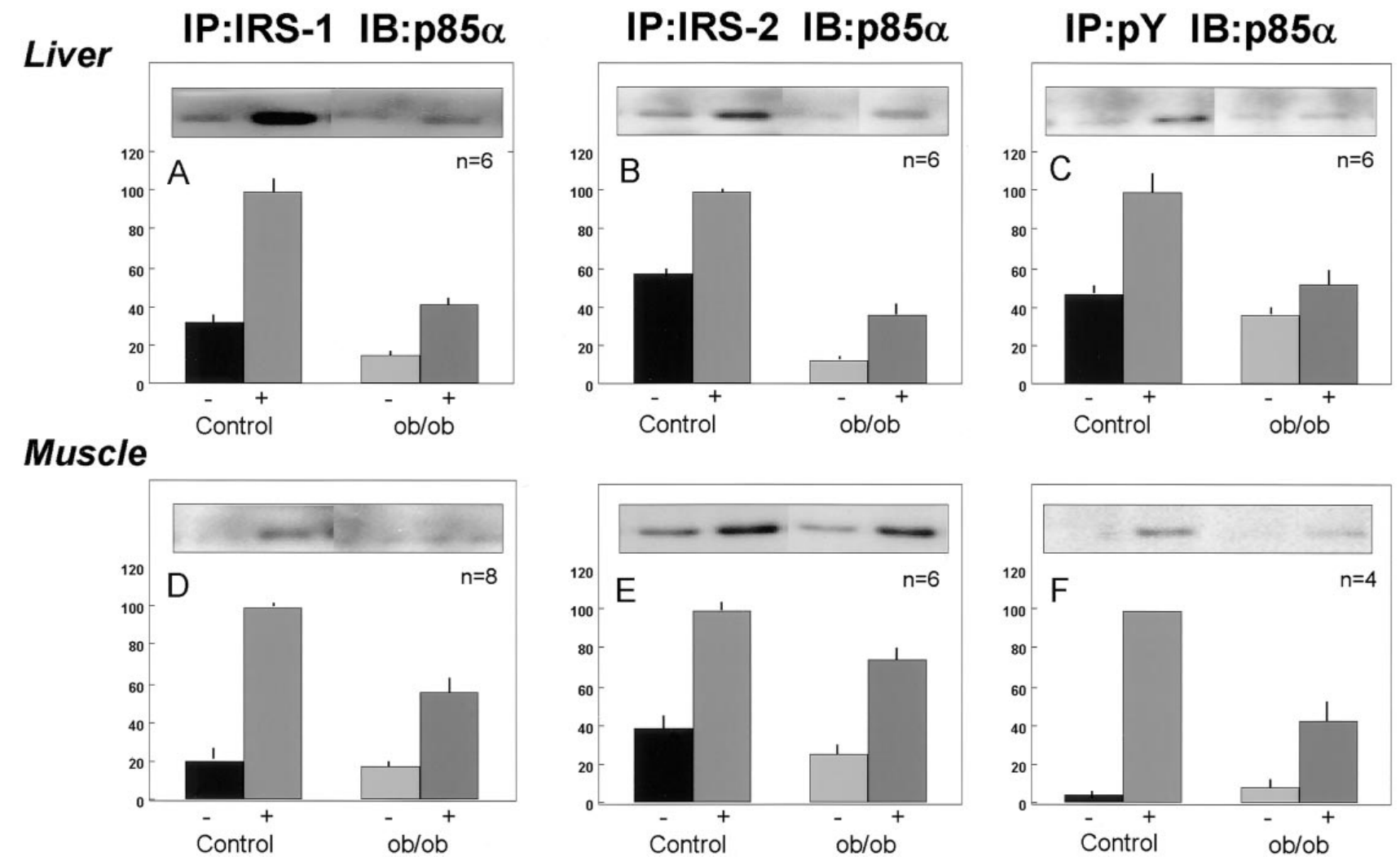

Figure 3. Association of IRS-1, IRS-2, and pY with p85 in liver and muscle of $o b / o b$ and $o b /+$ control mice. Animals were injected as described in Fig. 2. Equal amounts of protein were subjected to immunoprecipitation with COOH-terminal IRS-1, IRS-2, and pY antibodies, separated by SDS-PAGE, and Western immunoblotted with anti-p85 $\alpha$ antibody. The bar graphs show data quantification by ImageQuant (Molecular Dynamics) of results in liver $(A-C)$ and muscle $(D-F)$. Data are the mean \pm SEM of at least three independent experiments and are expressed as relative to control, assigning a value of $100 \%$ to the insulin-stimulated control mean.

\section{Discussion}

Insulin action at the cellular level is a complex network characterized by both alternative pathways and isoforms of the key proteins involved. At the first intracellular level are the multiple substrates of the insulin receptor. IRS-1 through IRS-4, Shc, and Gab-1 are all phosphorylated by the insulin receptor kinase and, with the exception of Shc, each of these possess multiple phosphorylation sites allowing for the interaction with several $\mathrm{SH} 2$ domain-containing proteins simultaneously $(7,9,10,16,31-33)$. These include the tyrosine phosphatase SHP2 (SHPTP2), the tyrosine kinase Fyn, the adaptor molecule GRB2, and the regulatory subunits of PI 3-kinase (7, 16, 34-37). At least seven potential forms of PI 3-kinase regulatory subunit are now known to exist. The first subunits described were $\mathrm{p} 85 \alpha$ and $\mathrm{p} 85 \beta$ and are products of separate genes (20-22). Both of these contain two SH2 domains separated by the p110 catalytic subunit binding region in the $\mathrm{COOH}$-terminal half of the molecule, and a SH3 domain and bcr homology region in the $\mathrm{NH}_{2}$-terminal half. Two alternative splicing events of $\mathrm{p} 85 \alpha$ result in removal of the $\mathrm{NH}_{2}$-terminal half and replacement with either 6 or 34 unique amino acids resulting in proteins termed p50 $\alpha$ and AS53 (also termed p55 $\alpha$ ) (24-27). p85 $\alpha$, AS53, and possibly p50 $\alpha$ can each also occur in two forms as a result of an alternative splice in the inter-SH2 domain region which replaces one amino acid with a nine- amino acid insert in a domain near the autophosphorylation site of the regulatory subunit and near the site of p110 binding (24). Finally, there is another PI 3-kinase regulatory subunit, derived from a third and separate gene, which encodes a protein of $55 \mathrm{kD}$, termed $\mathrm{p}^{\mathrm{PIK}}$. p55 $5^{\mathrm{PIK}}$ is $\sim 70 \%$ homologous to the p85 family members, being most similar to AS53 (28). Although PI 3-kinase activation has been implicated as a key intermediate in many metabolic actions of insulin, including regulation of glucose transport and gene expression, the functional differences among these various regulatory subunits is unclear, but may include involvement in specific signaling pathways, as well as subcellular localization (7).

Alterations in the early steps of insulin signaling have been recognized as an important component of many insulin-resistant states. Decreased insulin binding, decreased receptor kinase activity, decreased IRS-1 protein, and decreased IRS-1associated PI 3-kinase activity have all been demonstrated in $o b / o b$ mice and other models of NIDDM $(1,5,6,38,39)$. However, in view of the alternative substrates and pathways of insulin signaling, it is possible that there could be compensatory changes in either IRSs or various isoforms of PI 3-kinase which might minimize the impact of the alterations in IRS-1linked signaling. The present data indicate that both IRS-1 and IRS-2 are downregulated in liver and muscle of $o b / o b$ mice, although to a different extent. In liver, the decreases in IRS-2 protein levels and phosphorylation are greater than that for 

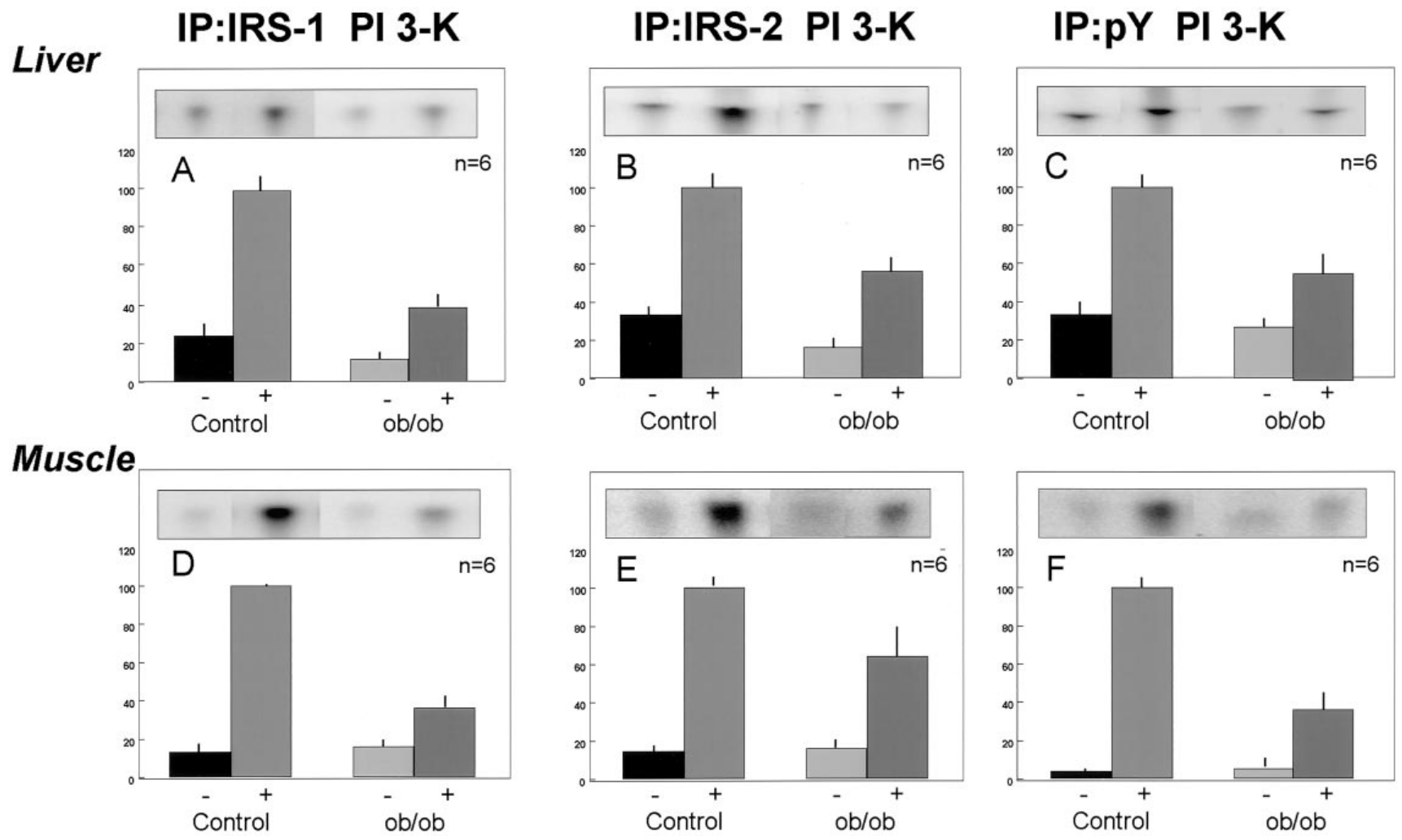

Figure 4. IRS-1-, IRS-2-, and pY-associated PI 3-kinase activities in liver and muscle of $o b / o b$ and $o b /+$ control mice. Animals were injected with $5 \mathrm{U}$ of regular insulin or its diluent in the portal vein. Liver and muscle tissue were removed 1 and 3 min later, respectively. Equal amounts of protein were subjected to immunoprecipitation with COOH-terminal IRS-1, IRS-2, and pY antibodies followed by PI 3-kinase assays as described in Methods. ${ }^{32} \mathrm{P}$ incorporation into PI 3-phosphate in immunoprecipitates of liver $(A-C)$ and muscle $(D-F)$ was quantified using a PhosphorImager (Molecular Dynamics). The band shown corresponds to PI 3-phosphate. Data are the mean \pm SEM of at least three independent experiments and are expressed as relative to control, assigning a value of $100 \%$ to the insulin-stimulated control mean.

IRS-1. This is accompanied by parallel decreases in association with IRS-1 and IRS-2 with p85 $\alpha$ and corresponding PI 3-kinase activities. In muscle, the decreases in IRS-1 and IRS-2 protein and phosphorylation levels are similar, while the reduction in IRS-1-associated PI 3-kinase activity is greater than that of IRS-2. The reduction of total pY-associated PI 3-kinase activity in liver was similar to that of IRS-1- and IRS-2-associated PI 3-kinase activity, whereas in muscle, the decrease in total pY-associated PI 3-kinase activity more closely paralleled the reduction of IRS-1-associated PI 3-kinase activity, consistent with previous observations $(13,40)$ that in liver, both IRS-1 and IRS-2 act as major IRSs and provide linkage to PI 3-kinase. Furthermore, in liver of $o b / o b$ mice, IRS-2 does not compensate for the reduced IRS-1 signaling, but also contributes to insulin resistance. In contrast, in $o b / o b$ muscle, IRS-1 is the dominant IRS and its downregulation appears to be mainly responsible for insulin resistance. Again, this is not compensated for by IRS-2 signaling, which is relatively minor and also reduced to some extent. Although it was not possible to evaluate the contribution of other substrates, such as IRS-3 (p60) $(32,33)$ or IRS-4 (41) to PI 3-kinase activation, our data emphasize the importance of coordinate changes in IRS-1 and IRS-2 in insulin signaling pathways in liver and muscle.

In addition to differential regulation of the IRS proteins, this study also revealed unexpected alterations in the levels of regulatory subunits of PI 3-kinase in liver of the $o b / o b$ mouse.
Previous studies in normal animals have suggested that $\mathrm{p} 85 \alpha$ is the major regulatory subunit of PI 3-kinase in liver, whereas AS53 is the dominant isoform in human skeletal muscle (24). In the present study, we find almost equal levels of p85 $\alpha$ and p50 $\alpha$ liver by Western blotting in liver of thin $o b /+$ mice. In the livers of the $o b / o b$ mouse, the spliced isoforms of the p $85 \alpha$ subunit of PI 3-kinase were preferentially overexpressed, and the expression of the normal p $85 \alpha$ isoform was reduced. This was especially true for the AS53/p55 $\alpha$ form which increased ninefold in obesity. Northern blot analysis demonstrated a downregulation of p85 $\alpha$ mRNA and increases in AS53 and p50 $\alpha$ mRNA that paralleled these changes at the protein level. In contrast, the levels of $\mathrm{p} 85 \beta, \mathrm{p} 55^{\mathrm{PIK}}$, and $\mathrm{p} 110 \alpha$ were not significantly altered in $o b / o b$ liver.

The upregulation of alternatively spliced isoforms of $\mathrm{p} 85 \alpha$ in liver of the diabetic $o b / o b$ mice raises the question whether alternative splicing of $\mathrm{p} 85 \alpha$ is caused by the hyperglycemia, hyperinsulinemia, or some other component of the diabetes and obesity pathogenesis. In a genetically derived, nonobese NIDDM mouse (29), and in the streptozotocin diabetic rat, no alterations in the level of $\mathrm{p} 85 \alpha$ or its isoforms are observed (Kerouz, N., D. Hörsch, and C.R. Kahn, unpublished data). Therefore, it is unlikely that upregulation of alternatively spliced isoforms in liver of $o b / o b$ mice is caused simply by high glucose and high insulin levels. On the other hand, a similar pattern of upregulation of AS53 and p50 $\alpha$ isoforms was ob- 

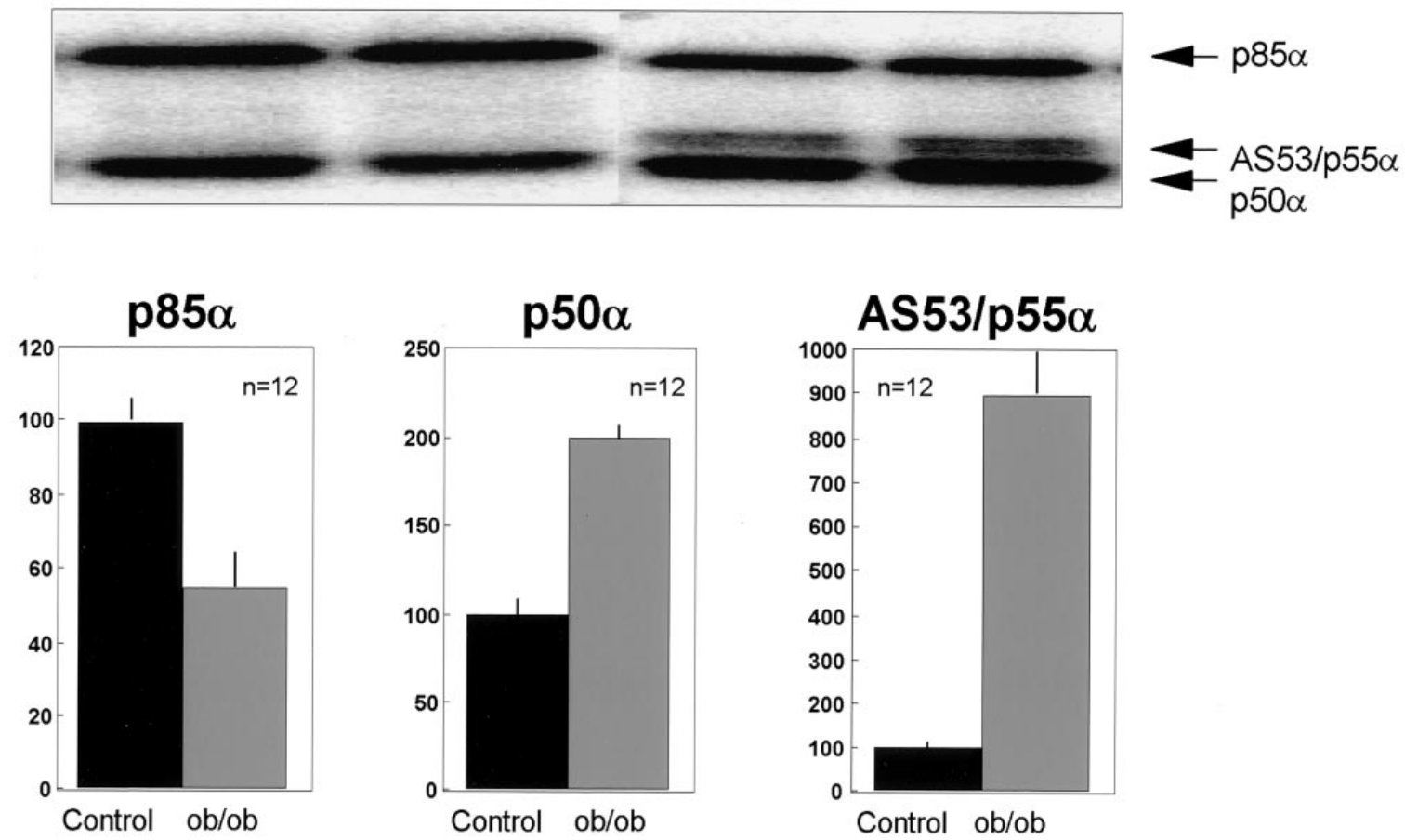

Figure 5. Expression of p85 $\alpha$ isoforms in liver of $o b / o b$ and $o b /+$ control mice. Equal amounts of protein were subjected to immunoprecipitation with polyclonal p $85 \alpha$ antibody, separated by SDS-PAGE, and Western immunoblotted with anti-p85 $\alpha$ antibody. The bar graphs show data quantification by ImageQuant (Molecular Dynamics). The migration of bands of 85, 53, and $50 \mathrm{kD}$ is indicated. Data are the mean \pm SEM of 12 independent experiments. They are expressed as relative to control, assigning a value of $100 \%$ to the control mean of p85 $\alpha$ expression.

served in the liver of other models of obesity, like the $d b / d b$ mouse and Agouti mouse (our unpublished observations).

To what extent these changes in $\mathrm{p} 85 \alpha$ and its isoforms contribute to changes in metabolic pathways in the liver is unknown, however PI 3-kinase activity is essential for differentiation and function of many cell types, including adipocytes (42), skeletal muscle cells (43), and hepatocytes (44). Whether these changes in PI 3-kinase isoform expression might also contribute to alterations in specific insulin pathways is not known. Preliminary studies in our laboratory have indicated that the
AS53 regulatory subunit binds less well to IRS-1 than does $\mathrm{p} 85 \alpha$. On the other hand, it has been reported recently that p50 $\alpha$ has a higher affinity for phosphorylated IRS-1 than the other p $85 \alpha$ isoforms (26). However, in regard to overall insulin signaling to PI 3-kinase, it is obvious that the increased levels of AS53 and p50 $\alpha$ isoforms in liver of $o b / o b$ mice do not compensate for the reduction in $\mathrm{p} 85 \alpha$ and the observed decrease in IRS-associated PI 3-kinase activity. Also, it has been reported that alternative splicing of the insulin receptor is increased in muscle tissue of NIDDM subjects (45-47). Thus, it is tempting
$\mathrm{C} \mathrm{Ob}$

C Ob

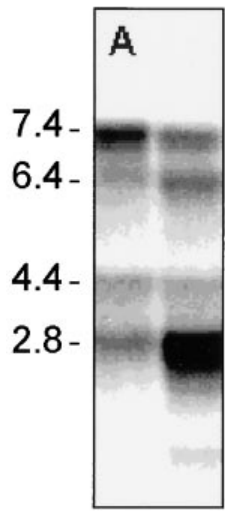

p85 Pan
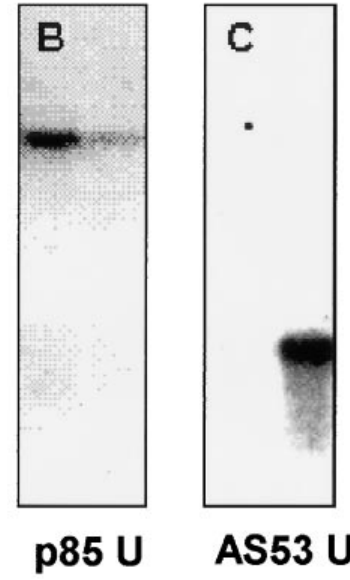

AS53 U
$\mathrm{C} \mathrm{Ob}$

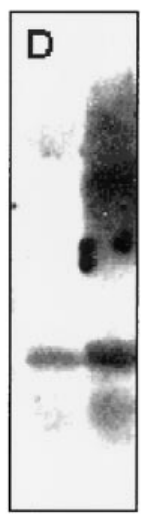

$p 50 \alpha U$
C Ob

$\mathrm{C} \mathrm{Ob}$

\section{$\mathrm{C} \mathrm{Ob}$}
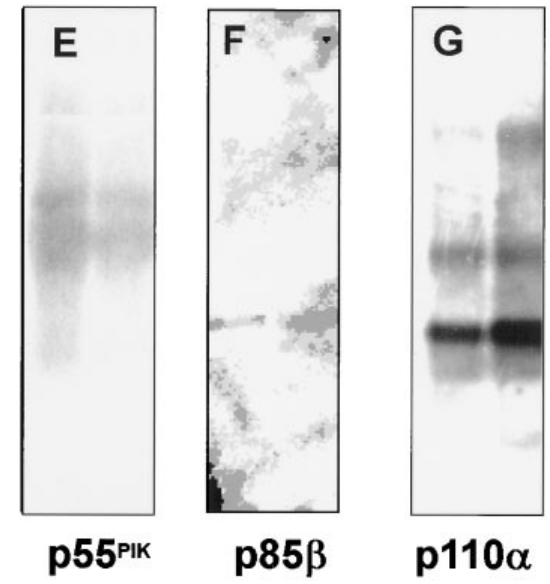

Figure 6. Differential expression of PI 3-kinase isoform mRNA in liver of $o b / o b$ mice. RNA samples of $o b /+$ and $o b / o b$ mice were subjected to Northern blotting using the indicated probes as described in Methods. $A$, $B, E, F$, and $G$ show total RNA blots $(40 \mu \mathrm{g}$ loaded/ lane). $C$ and $D$ depict poly(A) ${ }^{+}$RNA blots ( $2 \mu \mathrm{g}$ loaded/lane). Markers on the left denote transcript sizes. 
to speculate that changes in the alternative splicing of various signaling proteins may contribute to a range of alterations observed in the pathogenesis of diabetes and obesity.

In summary, we have shown that insulin resistance of obesity is associated with differential regulation of IRS-1, IRS-2, and several isoforms of PI 3-kinase regulatory subunits. The nature of these changes in liver and muscle is distinct and complex. These differential changes may produce differential alterations in insulin signaling in these two tissues and may contribute to the hepatic and muscular insulin resistance observed in obesity and diabetes.

\section{Acknowledgments}

The authors wish to thank Terri-Lyn Bellman for her secretarial assistance, and D. Antonetti, J. Bruning, and M.F. White for useful discussions and provision of reagents as described.

This work was supported by grants from the National Institutes of Health (DK-33201 and DK-36836) to C.R. Kahn and a grant from the Deutsche Forschungsgemeinschaft to D. Hörsch. Dr. Pons is a Fullbright Scholar and was supported by NIH grant DK-43808 (to MFW).

\section{References}

1. Soll, A.H., C.R. Kahn, D.M. Neville, Jr., and J. Roth. 1975. Insulin receptor deficiency in genetic and acquired obesity. J. Clin. Invest. 56:769-780.

2. Heydrick, S.J., D. Jullien, N. Gautier, J.F. Tanti, S. Giorgetti, E. Van Obberghen, and Y. Le Marchand-Brustel. 1993. Defect in skeletal muscle phosphatidylinositol-3-kinase in obese insulin-resistant mice. J. Clin. Invest. 91: 1358-1366.

3. Chua, S.C., Jr., W.K. Chung, X.S. Wu-Peng, Y. Zhang, S.M. Liu, L.A. Tartaglia, and R.L. Leibel. 1996. Phenotypes of mouse diabetes and rat fatty due to mutations in the OB (leptin) receptor. Science. 271:994-996.

4. King, P.A., E.D. Horton, M.F. Hirschman, and E.S. Horton. 1992. Insulin resistance in obese Zucker rat $(f a / f a)$ skeletal muscle is associated with a failure of glucose transporter translocation. J. Clin. Invest. 90:1568-1575.

5. Kahn, C.R., D.M. Neville, Jr., and J. Roth. 1973. Insulin receptor interaction in the obese hyperglycemic mouse. A model of insulin resistance. J. Biol. Chem. 248:244-250.

6. Folli, F., M.J.A. Saad, J.M. Backer, and C.R. Kahn. 1993. Regulation of phosphatidylinositol 3-kinase activity in liver and muscle of animal models of insulin-resistant and insulin-deficient diabetes mellitus. J. Clin. Invest. 92:17871794.

7. Cheatham, B., and C.R. Kahn. 1995. Insulin action and the insulin signaling network. Endocr. Rev. 16:117-142.

8. Myers, M.G., Jr., and M.F. White. 1995. New frontiers in insulin receptor substrate signaling. Trends Endocrinol. Metab. 6:209-215.

9. Sun, X.J., P.L. Rothenberg, C.R. Kahn, J.M. Backer, E. Araki, P.A. Wilden, D.A. Cahill, B.J. Goldstein, and M.F. White. 1991. The structure of the insulin receptor substrate IRS-1 defines a unique signal transduction protein. Nature. 352:73-77.

10. Sun, X.J., L.M. Wang, Y. Zhang, L. Yenush, M.G. Myers, Jr., E.M. Glasheen, W.S. Lane, J.H. Pierce, and M.F. White. 1995. Role of IRS-2 in insulin and cytokine signaling. Nature. 377:173-177.

11. Araki, E., M.A. Lipes, M.E. Patti, J.C. Bruning, B.L. Haag, III, R.S. Johnson, and C.R. Kahn. 1994. Alternative pathway of insulin signaling in mice with targeted disruption of the IRS-1 gene. Nature. 372:186-190.

12. Tamemoto, H., T. Kadowaki, K. Tobe, T. Yagi, H. Sakura, T. Hayakawa, Y. Terauchi, K. Ueki, Y. Kaburagi, S. Satoh, et al. 1994. Insulin resistance and growth retardation in mice lacking insulin receptor substrate-1. $\mathrm{Na}$ ture. 372:182-186.

13. Patti, M.E., X.J. Sun, J.C. Bruning, E. Araki, M.A. Lipes, M.F. White, and C.R. Kahn. 1995. 4PS/IRS-2 is the alternative substrate of the insulin receptor in IRS-1 deficient mice. J. Biol. Chem. 270:24670-24673.

14. Cheatham, B., C.J. Vlahos, L. Cheatham, L. Wang, J. Blenis, and C.R. Kahn. 1994. Phosphatidylinositol 3-kinase activation is required for insulin stimulation of pp70 S6 kinase DNA synthesis and glucose transporter translocation. Mol. Cell. Biol. 14:4902-4911.

15. Endemann, G., K. Yonezawa, and R.A. Roth. 1990. Phosphatidylinositol kinase or an associated protein is a substrate for the insulin receptor tyrosine kinase. J. Biol. Chem. 265:396-400.

16. Sun, X.J., D.L. Crimmins, M.G. Myers, Jr., M. Miralpeix, and M.F. White. 1993. Pleiotropic insulin signals are engaged by multisite phosphorylation of IRS-1. Mol. Cell. Biol. 13:7418-7428.
17. Hadari, Y.R., E. Tzahar, O. Nadiv, P. Rothenberg, C.T. Roberts, Jr., D. LeRoith, Y. Yarden, and Y. Zick. 1992. Insulin and insulinomimetic agents in duce activation of phosphatidylinositol 3 '-kinase upon its association with pp185 (IRS-1) in intact rat livers. J. Biol. Chem. 267:17483-17486.

18. Backer, J.M., M.G. Myers, Jr., S.E. Shoelson, D.J. Chin, X.J. Sun, M. Miralpeix, P. Hu, B. Margolis, E.Y. Skolnik, J. Schlessinger, and M.F. White. 1992. Phosphatidylinositol $3^{\prime}$-kinase is activated by association with IRS-1 during insulin stimulation. EMBO (Eur. Mol. Biol. Organ.) J. 11:3469-3479.

19. Hiles, I.D., M. Otsu, S. Volinna, M.J. Fry, I. Gout, R. Dhand, G. Panayotou, F. Ruiz-Larrea, A. Thompson, N.F. Totty, et al. 1992. Phosphatidylinositol 3-kinase: structure and expression of the $110 \mathrm{kD}$ catalytic subunit. Cell. 70: 419-429.

20. Escobedo, J.A., S. Navankasattusas, W.M. Kavanaugh, D. Milfay, V.A. Fried, and L.T. Williams. 1991. cDNA cloning of a novel $85 \mathrm{kD}$ protein that has $\mathrm{SH} 2$ domains and regulates binding of PI3-kinase to the PDGF $\beta$-receptor. Cell. 65:75-82.

21. Otsu, M., I. Hiles, I. Gout, M.J. Fry, F. Ruis-Larrea, G. Panayotou, A. Thompson, R. Dhand, J.J. Hsuan, N.F. Totty, et al. 1991. Characterization of two $85 \mathrm{kD}$ proteins that associate with receptor tyrosine kinases, middle-T/ pp60 ${ }^{\text {c-src }}$ complexes and PI3-kinase. Cell. 65:91-104.

22. Skolnik, E.Y., B. Margolis, M. Mohammadi, E.J. Lowenstein, R. Fischer, A. Drepps, A. Ullrich, and J. Schlessinger. 1991. Cloning of PI3 kinase-associated $\mathrm{p} 85$ utilizing a novel method for expression/cloning of target proteins for receptor tyrosine kinases. Cell. 65:83-90.

23. Kapeller, R., and L.C. Cantley, Jr. 1994. Phosphatidylinositol 3-kinase. BioEssays. 16:565-576.

24. Antonetti, D.A., P. Algenstaedt, and C.R. Kahn. 1996. Insulin receptor substrate 1 binds two novel splice variants of the regulatory subunit of phosphatidylinositol 3-kinase in muscle and brain. Mol. Cell. Biol. 16:2195-2203.

25. Inukai, K., M. Anai, E. van Breda, T. Hosaka, H. Katagiri, M. Funaki, Y. Fukushima, T. Ogihara, Y. Yazaki, M. Kikuchi, et al. 1996. A novel 55-kD regulatory subunit for phosphatidylinositol 3-kinase structurally similar to $\mathrm{p} 55^{\mathrm{PIK}}$ is generated by alternative splicing of the p $85 \alpha$ gene. J. Biol. Chem. 271: 5317-5320.

26. Inukai, K., M. Funaki, T. Ogihara, H. Katagiri, A. Kanda, M. Anai, Y. Fukushima, T. Hosaka, M. Suzuki, B.C. Shin, et al. 1997. p85 $\alpha$ gene generates three isoforms of regulatory subunit for phosphatidylinositol 3-kinase (PI 3-kinase), p50 $\alpha$, p 55 $\alpha$, and p $85 \alpha$, with different PI 3-kinase activity elevating responses to insulin. J. Biol. Chem. 272:7873-7882.

27. Fruman, D.A., L.C. Cantley, and C.L. Carpenter. 1996. Structural organization and alternative splicing of the murine phosphoinositide 3-kinase p $85 \alpha$ gene. Genomics. 37:113-121.

28. Pons, S., T. Asano, E.M. Glasheen, M. Miralpeix, Y. Zhang, T.L. Fisher, M.G. Myers, Jr., X.J. Sun, and M.F. White. 1995. The structure and function of $\mathrm{p} 55^{\mathrm{PIK}}$ reveals a new regulatory subunit for the phosphatidylinositol-3 kinase. Mol. Cell. Biol. 15:4453-4465.

29. Bruning, J.C., J. Winnay, S. Bonner-Weir, S.I. Taylor, D. Accili, and C.R. Kahn. 1997. Development of a novel polygenic model of NIDDM in mice heterozygous for $I R$ and $I R S-1$ null alleles. Cell. 88:561-572.

30. Klippel, A., J.A. Escobedo, M. Hirano, and L.T. Williams. 1994. The interaction of small domains between the subunits of phosphatidylinositol 3-kinase determines enzyme activity. Mol. Cell. Biol. 14:2675-2685.

31. Holgado-Madruga, M., D.R. Emlet, D.K. Moscatello, A.K. Godwin, and A.J. Wong. 1996. A Grb2-associated docking protein in EGF- and insulinreceptor signaling. Nature. 379:560-563.

32. Lavan, B.E., and G.E. Lienhard. 1993. The insulin-elicited 60-kD phosphotyrosine protein in rat adipocytes is associated with phosphatidylinositol 3-kinase. J. Biol. Chem. 268:5921-5928.

33. Smith-Hall, J., S. Pons, M.E. Patti, D.J. Burks, L. Yenush, X.J. Sun, C.R. Kahn, and M.F. White. 1997. The 60-kD insulin receptor substrate functions like an IRS-protein (pp60 IRS3) in adipose cells. Biochemistry. 36:8304-8310.

34. Skolnik, E.Y., C.H. Lee, A.G. Batzer, L.M. Vicentini, M. Zhou, R.J. Daly, M.G. Myers, Jr., J.M. Backer, A. Ullrich, M.F. White, and J. Schlessinger. 1993. The SH2/SH3 domain-containing protein GRB2 interacts with tyrosinephosphorylated IRS-1 and Shc: implications for insulin control of ras signaling. EMBO (Eur. Mol. Biol. Organ.) J. 12:1929-1936.

35. Freeman, R.M., Jr., J. Plutzky, and B.G. Neel. 1992. Identification of a human src homology 2-containing protein-tyrosine-phosphatase: a putative homolog of Drosophila corkscrew. Proc. Natl. Acad. Sci. USA. 89:11239-11243.

36. Myers, M.G., Jr., X.J. Sun, B. Cheatham, B.R. Jachna, E.M. Glasheen, J.M. Backer, and M.F. White. 1993. IRS-1 is a common element in insulin and insulin-like growth factor-I signaling to the phosphatidylinositol $3^{\prime}$-kinase. Endocrinology. 132:1421-1430.

37. Sugimoto, S., R.J. Lechleider, S.E. Shoelson, B.G. Neel, and C.T. Walsh. 1994. Expression, purification and characterization of SH2-containing protein tyrosine phosphatase, SH-PTP2. J. Biol. Chem. 268:22771-22776.

38. Saad, M.J.A., E. Araki, M. Miralpeix, P.L. Rothenberg, M.F. White, and C.R. Kahn. 1992. Regulation of insulin receptor substrate 1 in liver and muscle of animal models of insulin resistance. J. Clin. Invest. 90:1839-1849.

39. Saad, M.J.A., F. Folli, J.A. Kahn, and C.R. Kahn. 1993. Modulation of insulin receptor, insulin receptor substrate-1, and phosphatidylinositol 3-kinase in liver and muscle of dexamethasone-treated rats. J. Clin. Invest. 92:2065-2072. 
40. Tobe, K., H. Tamemoto, T. Yamauchi, S. Aizawa, Y. Yazaki, and T. Kadowaki. 1995. Identification of a $190 \mathrm{kD}$ protein as a novel substrate for the insulin receptor kinase functionally similar to insulin receptor substrate-1. J. Biol. Chem. 270:5698-5701.

41. Lavan, B.E., V.R. Fantin, E.T. Chang, W.S. Lane, S.R. Keller, and G.E. Lienhard. 1997. A novel $160 \mathrm{kD}$ phosphotyrosine protein in insulin-treated embryonic kidney cells is a new member of the insulin receptor substrate family. $J$. Biol. Chem. 272:21403-21407.

42. Tomiyama, K., H. Nakata, H. Sasa, S. Arimura, E. Nishio, and Y. Watanabe. 1995. Wortmannin, a specific phosphatidylinositol 3-kinase inhibitor, inhibits adipocytic differentiation of 3T3-L1 cells. Biochem. Biophys. Res. Commun. 212:263-269.

43. Kaliman, P., F. Vinals, X. Testar, M. Palacin, and A. Zorzano. 1996. Phosphatidylinositol 3-kinase inhibitors block differentiation of skeletal muscle cells. J. Biol. Chem. 271:19146-19151.

44. Skouteris, G.G., and E. Georgakopoulos. 1996. Hepatocyte growth factor-induced proliferation of primary hepatocytes is mediated by activation of phosphatidylinositol 3-kinase. Biochem. Biophys. Res. Commun. 218:229-233.

45. Norgren, S., J. Zierath, A. Wedell, H. Wallberg-Henriksson, and H. Luthman. 1994. Regulation of human insulin receptor RNA splicing in vivo. Proc. Natl. Acad. Sci. USA. 91:1465-1469.

46. Kellerer, M., G. Sesti, E. Seffer, B. Obermaier-Kusser, D.E. Pongratz, L. Mosthaf, and H.U. Haring. 1993. Altered pattern of insulin receptor isotypes in skeletal muscle membranes of Type II (non-insulin-dependent) diabetic subjects. Diabetologia. 36:628-632.

47. Mosthaf, L., B. Vogt, H.U. Haring, and A. Ullrich. 1991. Altered expression of insulin receptor types A and B in the skeletal muscle of non-insulindependent diabetes mellitus patients. Proc. Natl. Acad. Sci. USA. 88:4728-4730. 